\title{
Evaluating 'homegrown' research networks in Africa
}

\section{AUTHORS: \\ Camilla Adelle ${ }^{1}$ iD \\ Nico Elema² iD \\ Ereck Chakauya $^{3}$ \\ David Benson ${ }^{4}$}

\section{AFFILIATIONS:}

${ }^{1}$ Centre for the Study of

Governance Innovation,

University of Pretoria, Pretoria,

South Africa

${ }^{2}$ AU/NEPAD SANWATCE,

Stellenbosch University,

Stellenbosch, South Africa

${ }^{3} \mathrm{AU} / \mathrm{NEPAD}$ SANBio, Council

for Scientific and Industrial

Research, Pretoria, South Africa

${ }^{4}$ Department of Politics and the Environment and Sustainability Institute, University of Exeter,

Penryn, United Kingdom

\section{CORRESPONDENCE TO:}

Camilla Adelle

EMAIL:

camilla.adelle@up.ac.za

\section{DATES:}

Received: 07 Mar. 2017

Revised: 24 Oct. 2017

Accepted: 07 Dec. 2017

Published: 27 Mar. 2018

\section{KEYWORDS:}

research networks; policy formulation; science-policy interface; evidencebased policymaking; research collaboration

\section{HOW TO CITE:}

Adelle C, Elema N, Chakauya

$\mathrm{E}$, Benson D. Evaluating

'homegrown' research networks in Africa. S Afr J Sci. 2018;114(3/4), Art. \#2017-0070, 7 pages. http://dx.doi.org/10.17159/ sajs.2018/20170070

\section{ARTICLE INCLUDES: \\ $\times$ Supplementary material \\ $\times$ Data set}

\section{FUNDING:}

British Academy (Newton Mobility Grant no. NG150251); Leverhulme Trust International Networks Scheme (project number IN-2014-014)

(C) 2018. The Author(s). Published under a Creative Commons Attribution Licence.
Attempts to improve the policy environment have led to a growing pressure on governments in Africa to embark on policymaking that is more evidence based and considers a wide spectrum of scientific and indigenous knowledge. Local - or 'homegrown' - research networks on the continent can help strengthen the role of scientific knowledge in policymaking by increasing the capacity of researchers and by enhancing the visibility and communication of the research produced. While a large number of regional and sub-regional research networks have sprung up in Africa, the mere existence of networks does not guarantee their success. In reality, the impact of research networks on the science-policy interface depends on how well the networks operate in practice. We present a framework for evaluating the effectiveness of research networks in a way that is comparable across networks. The evaluation framework was used to evaluate two sub-regional research networks: the NEPAD Southern African Networks of Water Centres of Excellence (SANWACTE) and the NEPAD Southern African Network for Biosciences (SANBio). The evaluation revealed some shared constraints limiting the effectiveness of both networks, including uneven regional representation, asymmetry between network members, and difficulties in securing sufficient, diverse and sustainable resources. Further research into network design and funding models is suggested in order to enhance the role of these networks in providing locally appropriate knowledge for policymaking on the continent.

\section{Significance:}

- While a large number of research networks have sprung up in Africa, the mere existence of networks does not guarantee success.

- Uneven regional representation, power asymmetries, and limited funding constrain the effectiveness of research networks.

\section{Introduction}

Decision-makers in Africa are facing increasingly complex development challenges. Solving these challenges requires innovative solutions based on sound research and evidence. ${ }^{1}$ While it has been recognised that homegrown policy solutions have a higher probability of success than those developed off the continent, the lack of local research capacity has been identified as a major stumbling block to locally designed policy measures. ${ }^{2}$ Even when capacity is available, research findings are not always transferred to policymakers who may instead find themselves under pressure to use information and policy options promoted by international consultants and donors. ${ }^{3}$

A number of research networks are being established on the continent that could help strengthen local research capacity and offer an alternative source of evidence for policymaking in Africa. These research networks link researchers and research institutions working on similar issues from across the continent and/or at a subcontinental level. They aim to enhance collaboration and synergies between existing research programmes in order to reach a critical mass of highly trained and qualified researchers across the continent. Such a critical mass can increase the scientific quality (and hence legitimacy) of the research as well as its visibility to policymakers.

However, the mere existence of research networks does not guarantee such positive outcomes. The impact of networks depends on how (and how well) these networks function in practice. Yet there is an acute lack of literature evaluating the effectiveness of these networks. This deficit is partly because of difficulties in linking specific research to policy decisions, which invariably have multiple influences. There is also a lack of evaluation frameworks with which to analyse and compare networks.

We attempt to address this gap by presenting an evaluation framework for assessing the effectiveness of research networks and using it to evaluate two New Partnership for Africa's Development (NEPAD) research networks: the NEPAD Southern African Networks of Water Centres of Excellence (SANWACTE) and the NEPAD Southern African Network for Biosciences (SANBio). Both research networks respond to the African Union's 2005 Science and Technology Consolidated Plan of Action, which forms the basis for implementing NEPAD's Science and Technology programmes.

\section{The 'policy paradox' in Africa and the role of research networks}

\section{Policy inappropriateness in Africa}

There is an urgent need to improve what is broadly termed as 'the policy environment' on the continent so that policies are more effective from a managerial and delivery point of view. ${ }^{4} \mathrm{As}$ a result, there is growing pressure on governments in Africa to embark on policymaking that is more evidence based and considers a wide spectrum of scientific and indigenous knowledge. ${ }^{1}$ The ultimate objective is to overcome perceived shortcomings in the policy formulation and implementation with a view to making policies more effective. The logic behind this thinking is that Africa's economic crisis was, and still is, partly the product of accumulated policy distortions built up by inappropriate policies since independence in the 1960s. ${ }^{5}$ Inappropriate policies hamper economic growth, discourage private initiative, squander natural capital and can even cause widespread famine and civil wars. ${ }^{4}$ 
The temptation for African governments when formulating policies can be to rely on 'best practice' models developed outside the continent. In many cases these models are 'pushed' by international donors in a type of 'ideas aid'. ${ }^{2}$ In recent decades, development assistance has shifted away from investment financing to supporting policy reform ${ }^{6}$ largely because of the growing recognition that a precondition of economic growth is a good policy environment. ${ }^{7}$ However, the critical issue is not the recognition and copying of available knowledge but rather the ability to integrate this knowledge with local specific knowledge. This integration sets limits on the application of internationally available knowledge and determines its usefulness or lack thereof. ${ }^{8}$ Many development projects have been thought to fail because of a lack of adequate understanding of the local conditions on the continent - something African research institutions should be able to provide. ${ }^{8}$

The Structural Adjustment Programmes of the 1980s and 1990s, for example, were an ill-fated attempt by the Bretton Woods Institutions (World Bank and the International Monetary Fund) to improve policymaking in the continent by instituting severe economic reforms. ${ }^{4}$ The implementation of Structural Adjustment Programmes received widespread condemnation from both the international community and African intellectuals. ${ }^{4} \mathrm{~A}$ major criticism of the Structural Adjustment Programmes was that they did not bring about the expected positive results because they invoked policies that did not take into account the social, economic and political realities of the countries concerned. ${ }^{2}$ During this period (and still today), most countries in sub-Saharan Africa suffered from a common weakness in their institutions that meant there was a lack of capacity to carry out economic reforms. ${ }^{9}$ As a consequence, African governments relied heavily on external agencies and foreign consultants for research that was to be the foundation for policy decisions. According to Dollar and Svensson ${ }^{6}$, over a third of the Structural Adjustment Programmes failed because they were implemented in a poor policy environment, which was not fully understood by external researchers.

\section{The role of local research networks}

The 'policy paradox' in Africa is that at the same time as there is an acute need for local and appropriate research to feed into decision-making, there has been a stark lack of locally driven research conducted on the continent. In addition, what research does exists, is being underutilised in decision-making. ${ }^{10}$ Many policymakers and political leaders are not cognisant of the research ongoing in their countries or across the continent when they formulate policies. ${ }^{2}$ Research networks could help strengthen the research-policy relationship in Africa in two main ways: firstly, by increasing the capacity of researchers through collaboration and specialisation; and, secondly, by increasing the visibility and communication of the research produced. Furthermore regional and sub-regional research networks are well placed to tackle an increasing number of complex policy problems that do not stop at national borders.

Partly because of this trend, and because of broader patterns of globalisation and technological progress, cooperation in transnational networks has become an increasingly important feature of the interface between research and policy. ${ }^{8}$ This trend is also apparent in sub-Saharan Africa, which, while it lags behind much of the world in both the size and number of networks, is establishing some high-profile research networks ${ }^{8}$ such as the African Economic Research Consortium and the Council for the Development of Economic and Social Research in Africa. A recent list of African research networks includes over 50 such networks on the continent. ${ }^{11}$ Regional research networks aim to strengthen collaboration in particular fields in order to contribute to applied research and quality teaching. The members of these networks are usually higher education institutions and/or research institutes across specific sub-regions, such as southern Africa, but sometimes also across the whole of Africa.

According to Bhorat ${ }^{12}$, these networks offer a range of advantages, which include opportunities to engage with peers and institutions outside one's own country and to learn from their experiences; useful cross-pollination of ideas in diverse areas; shared operational, financial and human resource management; and collective dissemination and fund-raising activities. Ideally, a network - if strong and well-functioning - can assist weaker partners in the network in a way that does not draw too heavily on its own internal time and resources. ${ }^{12}$ Bhorat cautions that the existence of regional and sub-regional research networks does not necessarily mean that the research policy relationship is strengthened:

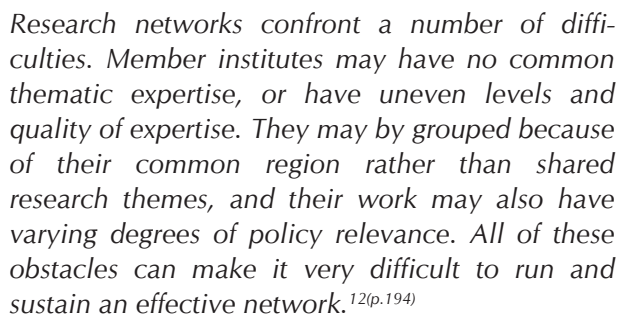

So while research networks in principle can help strengthen the research policy relationship, the mere existence of networks does not guarantee this effect. The actual impact of research networks on the science-policy relationship depends on how well the networks operate in practice, i.e. network effectiveness.

\section{Analytical framework and methodology}

The literature on networks is vast and stretches across numerous disciplines including health sciences, management and organisational studies, political science, social science and computer science. For the purposes of this paper, we define networks as a set of autonomous organisations that come together in a bid to reach shared goals. Despite the sizable literature on networks, few studies have focused on examining the relationship between networks structure and activities and effectiveness. However, evaluating network effectiveness is critical to understanding if networks are improving the science-policy interface. This feature is important not only to the network members and funders but also to the wider community served by these networks, such as policymakers and the public that will ultimately benefit by the improved problem-solving and policymaking. Criteria for network effectiveness vary, but generally three distinct elements of networks are identified in the literature: structure, process and outcomes. These elements are outlined below based primarily on a framework developed by the Network Impact and Center for Evaluation Innovation ${ }^{13}$ with some adjustments inspired by Hill ${ }^{14}$ as well as Provan and Milward ${ }^{15}$.

\section{An analytical framework for evaluating networks}

\section{Network structure}

The connections between the network members are the essential glue that binds a network together. Therefore, it is important to know if efforts within the network to weave members' ties to each other are resulting in efficient and effective pathways for collective learning and action. Network structure therefore has three components that can be assessed: (1) network membership (i.e. who are the network members); and (2) membership cohesion (i.e. how connected are the members) and (3) network centrality (i.e. the importance and influence of the partnership/network/collaboration within the power structure and organisational context of its wider community, e.g. in policymaking circles).

\section{Network process}

A crucial factor for a network's well-being is its capacity to sustain the active enthusiasm and commitment of voluntary members and enable their ability to work together to achieve shared goals. Network process has three dimensions that can be assessed: (1) resources (i.e. what resources are shared in the network); (2) infrastructure, or the internal systems and structures that support the network (i.e. how is the communication, rules and processes organised and is there a central administrative structure); and (3) added value, or the network's capacity for joint value creation (i.e. are the members working together to achieve shared goals).

\section{Network outcome}

Ultimately, most networks have a goal of achieving a particular type of social change. They come together for a purpose, and while network structure and process dimensions are important to their ability to 
achieve those results, it is important to know if the network itself is making a difference. Network results have two dimensions that can be assessed: (1) interim outcomes, or the results achieved as the network works toward its ultimate goal or intended impact; and (2) the goal or intended impact itself (e.g. a policy outcome was achieved).

Much of the literature on networks tends to focus on network composition and function rather than on the elements crucial to meeting network goals or indeed ascertaining if and how these goals were achieved. In some ways, the literature implies that establishing a network is a huge success in itself; however, this is not necessarily the case, as our consideration of two NEPAD research networks illustrates.

\section{Research methodology}

In our research, the analytical framework set out above was operationalised into a set of specific evaluation questions for each of the three network elements, namely 'network structure', 'process' and 'outcome'. These questions are set out in Table 1 and were used to guide the analysis. The evaluation took place between September 2016 and January 2017. The first stage of the evaluation primarily focused on the qualitative desktop documentary analysis of the many documents charting the history, strategy and achievements of the two networks including annual reports, business plans, brochures, presentations at conferences, webpages, as well as internal and external reviews of the networks. The specific documents used are cited in the text to follow. The desktop documentary analysis was followed by semi-structured discussions with the two network coordinators (N.E. and E.C.). Additional information in the form of direct participant observations of the two networks was provided through these discussions by the authors based on their interactions with the networks over several years.

Two NEPAD-affiliated networks were evaluated: The NEPAD Southern African Network of Water Centres of Excellence (SANWACTE) and the NEPAD Southern African Network for Biosciences (SANBio). Both networks are part of continent-wide networks established in all five African Union regions under the framework of NEPAD Centres of Excellence for Science and Technology. These cases were selected partly because their similar geographical scope and common mandate make them broadly comparable.

Table 1: Evaluation framework for the three network elements (structure, process and outcomes)

\begin{tabular}{|c|c|c|}
\hline Element & Focus & Evaluation question \\
\hline \multirow{10}{*}{ Structure } & \multirow{3}{*}{ Membership } & Who participates in the networks and what is their role? \\
\hline & & Has the network assembled members with the capacities needed to meet network goals? \\
\hline & & Who is not included/connected that should be? \\
\hline & \multirow{5}{*}{ Cohesion } & How are the members connected? \\
\hline & & How efficient are these connections? \\
\hline & & How dependent is the network on a small number of actors? \\
\hline & & What is flowing through the network - e.g. information and/or other resources? \\
\hline & & Is the structure adjusted to meet changing network needs and priorities? \\
\hline & \multirow{2}{*}{ Centrality } & To which forums and actors is the network itself connected? \\
\hline & & From where did the mandate for the network come? \\
\hline \multirow{12}{*}{ Process } & \multirow{4}{*}{ Resources } & Has the network secured needed material resources? \\
\hline & & How diverse and dependable are these resources? \\
\hline & & How are the members contributing resources to the network? \\
\hline & & Is the network adapting its business plan over time? \\
\hline & \multirow{4}{*}{ Infrastructure } & What infrastructure is in place for network coordination and communications? \\
\hline & & Are these systems efficient and effective? \\
\hline & & What are the network's governance rules and how are they followed (and who developed them)? \\
\hline & & How are the network's internal systems and structures adapting over time? \\
\hline & \multirow{4}{*}{ Collective value-added } & Do all the members share a common purpose for the network? \\
\hline & & Are the members working together to achieve shared goals, including those that evolve over time? \\
\hline & & Are all the members contributing to the networks efforts? \\
\hline & & Are the members achieving more together than they could alone? \\
\hline \multirow{5}{*}{ Outcomes } & \multirow{2}{*}{ Interim outcomes } & What signs of progress/outputs are there? \\
\hline & & Do these outputs show a clear progression towards the ultimate goals of the network? \\
\hline & \multirow{3}{*}{ Ultimate goals } & What impacts are expected at a community level (e.g. more input of research into policy)? \\
\hline & & What impacts are expected at an organisational level (e.g. benefits for the members' organisations)? \\
\hline & & If these impacts can be observed, can a plausible case be made that the network contributed to them? \\
\hline
\end{tabular}

Sources: Based on Network Impact and Center for Evaluation Innovation ${ }^{13}$; Hill'14; Provan and Milward ${ }^{15}$ 
The networks were also selected because of the authors' knowledge of these networks, which facilitated a more intimate evaluation than the selection of other similar networks would have. Further information on the mandate and history of the two networks is given below.

\section{Network 1: An evaluation of the Southern African Network of Water Centres of Excellence}

\section{Network background}

The mandate to establish SANWATCE came from a joint declaration in 2006 from the African Ministerial Council on Science and Technology and the African Ministers' Council on Water to establish Networks of Water Centres of Excellence across the African continent. NEPAD was to act as the facilitating agent. The intention was to establish networks in all five AU regions of the African continent. So far two networks have been set up: SANWATCE covering the Southern African Development Community (SADC); and the NEPAD Western African Network of Water Centres of Excellence (WANWATCE) covering the Economic Community of West African States. SANWATCE's mission is to 'contribute to the improved human and environmental well-being through research and development in water and sanitation'16 through pursuing the following objectives: facilitate and conduct selected research on water issues; serve as a higher education soundboard to the SADC region on regional water matters; collaborate with other networks and institutions in specialised areas; set the SADC water research agenda; and establish a continental water research agenda which is populated from the SADC regional water agenda. ${ }^{16}$

\section{Network structure}

SANWATCE consists of 11 higher education and research institute members (Table 2). The network Secretariat is hosted by Stellenbosch University in South Africa. Members of the network were selected according to a set of transparent criteria posted on the network's website. ${ }^{17}$ One of the main challenges has been to draw in network members from across all 15 SADC countries. Despite ongoing efforts to recruit new members, SANWATCE is made up of members from just eight countries with four members in South Africa. Countries currently without a network member are Angola, Democratic Republic of the Congo, Tanzania, Seychelles, Madagascar, Swaziland and Lesotho. The over-representation of South Africa as a relatively well-resourced country with strong tertiary institutions is unsurprising, as is the lack of participation of smaller states such as Lesotho and Swaziland. However, in general, wider coverage of the networks remains a challenge that the network has not yet been able to adequately address.

\section{Table 2: $\quad$ SANWATCE Members}

\begin{tabular}{l|l}
\hline \hline \multicolumn{1}{c|}{ Institution } & \multicolumn{1}{c}{ Country } \\
\hline Stellenbosch University & South Africa \\
\hline Eduardo Mondlane University & Mozambique \\
\hline University of KwaZulu-Natal & South Africa \\
\hline University of the Western Cape & South Africa \\
\hline University of Malawi & Malawi \\
\hline University of Zambia & Zambia \\
\hline University of Botswana & Botswana \\
\hline CSIR Natural Resources and Environmental Unit & South Africa \\
\hline $\begin{array}{l}\text { Polytechnic of Namibia (recently renamed Namibian University } \\
\text { of Science and Technology) }\end{array}$ & Namibia \\
\hline National University of Science and Technology, Zimbabwe & Zimbabwe \\
\hline University of Mauritius & Mauritius \\
\hline
\end{tabular}

The members are connected through an annual face-to-face Steering Committee Meeting of members as well as additional online meetings. Ad-hoc meetings between members also occur in conjunction to (relatively rare) project meetings. However, it is the Secretariat that plays the most prominent role in maintaining network cohesion through communication with the members via email and the website. In principle, the member institutions are to coordinate with other universities and institutes in their country but in practice this does not happen systematically.

The high degree of centrality of SANWATCE is one of the network's main strengths. The joint endorsement from both the African ministers responsible for water and also ministers of science and technology (see above), provide a strong political mandate from regional institutions, as does the positioning of the network as a NEPAD flagship programme. In addition, SANWATCE has a close relationship with SADC (which approves its business plans) and reports its research findings regularly to its Technical Advisory Committee. ${ }^{18}$ Furthermore, the network is the implementing agent for the Water Research Fund for Southern Africa (WARFSA), a programme of SADC Water Division. ${ }^{19}$ The network is also a key partner in the Joint Africa-EU Strategy, which provides a high-level cooperation platform for the EU and African partners, as well as the European Union Water Initiative, and its Africa Working Group. Therefore, SANWATCE occupies not only a central position amongst regional decision-making but also inter-regional planning and cooperation.

\section{Network process}

The most fundamental challenge for the network has been to access sufficient and sustainable sources of funding. Although the network was initiated and promoted by regional institutions (i.e. AU, NEPAD, SADC), these institutions (and their member states) have not provided the necessary resources to set up and maintain the network. Funding was eventually agreed by the South African Department of Science and Technology (DST) in $2009^{18}$ for maintaining the core activities of the Secretariat. DST has continued to provide, and even increase, this funding over the lifetime of the network. In the financial years 2016/2017 and 2017/2018, DST provided ZAR2.5 million each year.

Wider research and capacity-building activities across the network, albeit fairly modest in scale, have been funded by a single international donor, the EU. 20,21 Between 2009 and 2018, the European Commission allocated approximately EUR2.3 million ${ }^{22}$ for SANWATCE activities, which is considerably less than the EUR11.5 million requested in the 2013-2018 Business Plan. Therefore, funding is extremely scarce. While it is realised that in the long term SANWATCE must find ways to raise more resources and be sustainable, ${ }^{18}$ so far there has only been limited support from other member states outside of South Africa usually through in-kind contributions. In addition, in the current fiercely competitive environment, funding applications submitted to international donors and research funding bodies by the Secretariat on behalf of the network have so far been unsuccessful.

In the absence of substantial projects and research activities, the infrastructure, especially the Secretariat, has become particularly important in maintaining the network. The financial support from DST (as well as support in kind from Stellenbosch University) has helped ensure a strong secretariat run by two full-time and three part-time staff members. Besides maintaining communication with the network members, the Secretariat performs a number of functions, including: representing the network at international forums and in discussions with external partners; liaising with regional partners, especially in SADC; coordinating the legal affairs of the network as well as the day-to-day functioning of the network; preparing and submitting joint research proposals on behalf of the network; and creating inventories of expertise, skills and high end equipment. The strong role of the Secretariat, coupled with the dominance of South African actors and funding in the network, has, however, created tensions surrounding the governance of the network; a review of the network in 2012 reports that 'a perception may exist among other participating countries that they are less on the leading side on SANWATCE decisions and more as followers and recipients of approaches from the members within South Africa'23. 
The main collective advantage of the networks is branding as a NEPAD flagship network, which adds considerable legitimacy to joint funding proposals and approaches to donors. However, although it is perceived to be a significant advantage by stakeholders, it has not yet translated into a significant flow of resources into the network. The network has also helped focus attention (and indeed create) the SADC research agenda, which acts as a common vision in future research. However, with limited funding to carry out research and even less from sources within the SADC region, it is not clear how far the network will be able to implement this agenda. One recent promising initiative funded by the DST provides limited funding for postgraduate students in each member institution to work on projects within this research agenda, but this amount is insignificant compared to the research needs identified.

\section{Network outcome}

It is too early by far to assess the network in terms of ultimate outcomes (i.e. achieving their goals of contributing through research to improving societal and environmental challenges). However, various interim outcomes can be assessed. For example, the network has contributed to improving the collaborations and contact between the institutions and researchers involved. ${ }^{24}$ The network has established a strong presence within relevant forums in SADC and internationally. SANWATCE has also fulfilled one of its objectives to contribute to the creation of a SADC research agenda in the sector.

\section{Case 2: An evaluation of the Southern Africa Network for Biosciences}

\section{Network background}

The NEPAD Southern Africa Network for Biosciences (SANBio) was established in 2005 within the framework of NEPAD's Centres of Excellence for Science and Technology. It covers the SADC region as one of five sub-regional networks established in the AU under the African Biosciences Initiative. ${ }^{25}$ This initiative is directed at facilitating the establishment of state-of-the-art research and development facilities that can enable institutions to pool resources to address common biosciences challenges. The focus areas include human health, agriculture productivity, sustainable water resource use management, biodiversity management and sound environmental management. SANBio's objectives are to: support an effective and dynamic regional research network; enhance human and infrastructure capacity; and develop and commercialise innovation products in health and nutrition. ${ }^{26}$

\section{Network structure}

SANBio brings together partners from five southern African countries. The network is structured on a 'hub and node' model facilitated by a secretariat. The hub is located at the Council for Scientific and Industrial Research (CSIR) in South Africa and provides financial management and operational support to the Secretariat (which is also hosted at the same location). Country nodes located at research and/or higher learning institutions throughout the region (Table 3) participate in regional research, development and innovation activities in different technical themes, including inland fisheries; indigenous knowledge systems; mushrooms; livestock; bioinformatics; traditional medicines for HIV/ AIDS; and plant genetics. As with SANWATCE, securing commitment and participation from across the SADC region continues to be a challenge and despite ongoing efforts, several SADC states (e.g. Seychelles, Madagascar, Angola) have not been very active in the network.

Cohesion in the network is mainly created through the research projects conducted within the nodes. SANBio projects must include three or more SADC countries and so provide opportunities for creating links between other network partners as well as international collaborating partners. Eight projects were initially funded from SANBio funds (see below) in the first phase of the network (i.e. 2009-2012) and broadly covered the topics of the six nodes. In the second phase of the network (2013-2018), 5 flagship projects and 10 smaller seed projects are being directly funded by the network (with matching national funding). Cohesion across the network (and between nodes) is less evident but the role of the Secretariat is critical here (as it was in SANWATCE). The nodes report back on progress on projects to the Secretariat which also maintains communication across the network via email and through the website. The nodes are also supposed to coordinate and engage with other universities and institutes that work in their areas of specialism across the SADC region; however, there is limited evidence available on the extent to which this occurs.

As with SANWATCE, the centrality of the network is relatively high, which in principle puts SANBio in a strong position to impact on regional decision-making. The African Biosciences Initiative - of which SANBio is a part - responds to the AU's 2005 Science and Technology Consolidated Plan of Action, which forms the basis for implementing NEPAD's Science and Technology programmes. SADC ministers also endorse the business plans of the network. However, an evaluation of the network after its first phase questions whether these top-down linkages between the network and the regional political institutions were enough to link the policies and strategies across the region with the research on the ground. The evaluation also argues that connections between the network and the private sector have also been neglected. ${ }^{27}$

\section{Network process}

SANBio has been able to raise significantly more resources for projects than SANWATCE and is perhaps making more headway in securing diverse and sustainable sources of funding for the future. However, attracting sufficient funds is still the main challenge of the network and substantially limits its activities vis a vis its business plan. Similar to SANWATCE, funding for the network has been provided by both DST and international donors. In 2005-2006, a grant of CAD450 000 was made available to SANBio by the Canadian International Development Agency and about ZAR1.3 million was provided by DST. These funds were to prepare a business plan, which was marketed to donors for funding support. In 2009, the Finnish Ministry of Foreign Affairs and the government of South Africa launched the Finnish-Southern African Partnership Programme to Strengthen NEPAD/SANBio (BioFISA).

In the first phase (2009-2011), the South African government, through DST, provided ZAR9 million and the Finnish Government EUR3 million. ${ }^{28}$ The purpose of BioFISA was to strengthen the operational capacity of SANBio and to support it in rolling out its business plan, which included the eight initial research projects mentioned above. ${ }^{28}$ The Finnish and South African governments agreed to renew the BioFISA programme for a second period (2015-2019) with a total budget of EUR7.82 million.

Table 3: $\quad$ SANBio Members

\begin{tabular}{l|l|l}
\hline \hline \multicolumn{1}{|c|}{ Institution } & \multicolumn{1}{|c}{ Country } & \multicolumn{1}{c}{ Node } \\
\hline CSIR & South Africa & Traditional medicine/HIV and HIV/microbicides \\
\hline Bunda College of Agriculture (now LUANAR), University of Malawi & Malawi & Fish biodiversity \\
\hline University of Namibia & Namibia & Technology transfer on mushroom farming \\
\hline SADC Plant Genetic Resources Centre (SPGRC) & Zambia & Conservation of plant genetic resources (gene banks) \\
\hline University of Zambia (UNZA)/National Institute for Scientific and Industrial Research (NISIR) & Zambia & Livestock production \\
\hline University of Mauritius & Mauritius & Bioinformatics \\
\hline North-West University & South Africa & Indigenous knowledge systems \\
\hline
\end{tabular}


In the second phase, several new initiatives are aimed at generating diverse and sustainable sources of income - which was seen as a weakness of the first phase of the network. For example, member states must pay a $40 \%$ contribution toward projects in which they participate $-20 \%$ in cash and $20 \%$ in kind (e.g. office space, electricity, water, transport and staff time) $)^{29}$; and more emphasis is placed on commercialisation and 'bring-to-market' objectives involving the private sector $^{30}$. While there are some signs that these efforts are beginning to pay off (e.g. five large externally funded projects are expected to bring in USD1.7 million of investments in the financial year 2016/2017), ${ }^{31}$ it seems unlikely that the ambitious targets in the business plan for leveraging external funds will be met. In the 2006-2011 business plans, the target was to raise USD50 million (while EUR6 million in cash and ZAR14 million in kind was raised). In the 2013-2018 business plan, the target is to raise USD80 million. ${ }^{30}$

SANBio's infrastructure is composed of three main components: a central Hub, a Secretariat, and also a Steering Committee consisting of one representative from each member state. The Hub is intended to provide financial management and operational support to the Secretariat. In practice, however, various challenges have arisen from the location of the Hub in a national institution like CSIR, including that its processes and payment procedures are designed to work with projects within South Africa and not internationally. ${ }^{31}$ The Secretariat also has had internal challenges. For example, the Secretariat staff are on short-term contracts without certain benefits which makes it difficult to attract and retain the best talent to SANBio. Furthermore, the role of the Steering Committee was criticised after the first phase for contributing to an overly top-down and bureaucratic governance structure. Changes were consequently made in the second phase of the network. In 2015, the SANBio Secretariat received a boost in numbers as the team both changed and expanded to six staff members in 2015/2016. ${ }^{31}$ In addition, CSIR appointed a Hub Manager who may be able to better promote interaction between the network and the Hub. ${ }^{31}$

The main activities of the network involve joint research and development projects. In the evaluation of the first phase of the projects, several stakeholders noted that network creation had been achieved within each project. ${ }^{27}$ However, other stakeholders emphasised that beyond these specific projects, the 'network of networks' had yet to be established. Therefore, although there appears to be an indication that network members are working together to achieve shared research goals within projects and nodes, it is not yet clear how effective this collaboration is in practice.

\section{Network outcome}

While it is still early to assess the network in terms of its ultimate goal of addressing common African bioscience challenges, it is possible to evidence achievements within the projects and nodes, in terms of training workshops, products development, publications and students trained etc. ${ }^{27,30}$ The network is also participating in a number of technical working groups under the AU Research for Health Strategy and is involved in SADC Science, Technology and Innovation and Health Sector programmes. Other interim outcomes achieved so far have been the increasing level of funds being raised outside of the network and its core funders.

\section{Network constraints and facilitators}

The evaluation framework allows us to identify common constraints and facilitators across the two networks that constrain and/or enhance their effectiveness. Firstly, both networks struggled to overcome issues of representation across the regions. Although research networks are designed to build capacity and pool resources so that weak members can benefit from the capacity of stronger members, certain basic criteria need to be reached before joining the network is feasible. Secondly, certain network members inevitably have more resources than others, which can create tensions and asymmetries in the network. In both networks, South African institutes were over-represented. The South African government was also a major donor of the networks. It is therefore perhaps not surprising that, at times, network members from other countries felt that they were not equal network members. Thirdly, funding was the key constraint in both networks. International donors are becoming increasingly interested in funding research networks but there remains a question about whether this approach focuses the agenda away from local priorities. Increasing funding from SADC members would overcome this danger, but SADC members tend to be cash-strapped and focused on more immediate priorities within their own political agendas. In addition, only South Africa has a dedicated department for science and technology, while in other countries there are also strongly competing areas for science support.

The two networks evaluated also share some common strengths that facilitated them in their day-to-day activities despite these challenges. Firstly, both networks benefit from strong secretariats. In the absence of sufficient project funding, the infrastructure of a network becomes critical in maintaining the network. Strong secretariats are therefore essential because top-down hierarchical structures are unlikely to be accepted by network members in what are essentially flat governance structures. Secondly, both networks have a high level of centrality in terms of their influence over regional research agendas and links to decision-makers at sub-regional and regional levels. This is connected to a third strength of both networks: there was a clear advantage for the network members in joining together under the banner of the NEPAD networks in terms of visibility with both funders and policymakers. This shared branding enhanced the legitimacy and credibility of the institutions when operating under the network. While this advantage has yet to be fully realised, especially in terms of attracting funding, it does seem to be a real prize on the horizon.

\section{Conclusions}

Demand for more evidence-based policy is increasing across Africa as most political systems undergo a process of liberalisation, thus putting to an end the monopoly of policy analysis and increasing the public scrutiny of policy action. ${ }^{8}$ In addition, policy problems are becoming more complex and transnational, prompting a greater need for policymaking at a regional level. ${ }^{8}$ If African researchers and research institutions are to play an effective role in these changing dynamics, they need to grow and increase their capacity. ${ }^{7}$ Regional research networks aim to pool resources, share experiences and build capacity with the aim of increasing the quality and the impact of research. We argue that the mere existence of networks, however, is not enough to make the science-policy interface more porous to homegrown policy solutions: these networks must function effectively. The evaluation of the SANWATCE and SANBio networks here, however, reveals some shared challenges which are limiting their effectiveness, including achieving adequate regional representation; unequal contribution and power relations between members; and securing sufficient, diverse and sustainable resources.

While the relationship between evidence and policymaking still needs to be better understood around the world, there is a particular gap in the literature on this process in developing countries. This article was aimed at helping to fill this research gap by presenting an evaluation framework that can be used to evaluate other research networks on the continent. The objective of the evaluation framework is not to provide the type of indepth review of the networks that donors and other stakeholders might require to report and monitor progress, but instead to provide a broadbrush outline of the networks in a way that can be compared across networks. This exercise will help build up a picture of how (and how well) research networks on the continent are operating in practice. Most importantly, the comparative evaluation of research networks on the continent should help to promote critical thinking about these networks that could help to develop recommendations on how these networks can be improved and better designed in future. With over 50 such research networks listed on the continent, ${ }^{11}$ we would argue that this type of research is long overdue.

However, at this stage (i.e. with the evaluation of only two research networks) many more research questions are raised than are answered. For example, how can research networks be designed in such a way as to include policymakers and so better bridge the divide between the "two communities' model of policymaking? Related to this question, we might ask: Can networks be designed to better incorporate indigenous knowledge into science and so help break down perceptions that science is the 
domain of the imperialist West while Africa can only contribute cultural experiences? Can research networks help overcome the dichotomy in countries that are more globally connected and those that are not? How does international donor funding influence these networks? Does it risk missing the most relevant issues for African countries? Answering these questions will be critical to understanding how localised research networks can better input into future policymaking in Africa.

\section{Acknowledgements}

This research was funded by the British Academy Newton Mobility Grant (grant no. NG150251) and the Leverhulme Trust International Networks Scheme (project number IN-2014-014).

\section{Authors' contributions}

C.A. was the lead author and team coordinator; N.E. was responsible for the concept design and gave input into the empirical section on SANWATCE; E.C. gave input into the empirical section on SANBio; and D.B. gave input into the overall research design and draft text.

\section{References}

1. Godfrey L, Funke N, Mbizvo C. Bridging the science-policy interface: A new era for South African research and the role of knowledge brokering. S Afr J Sci. 2010;106(5-6):44-51. https://doi.org/10.4102/sajs.v106i5/6.247

2. Marouani AM, Ayuki ET. Introduction. In: Ayuk ET, Mohamed AM, editors. The policy paradox in Africa: Strengthening links between economic research and policymaking. Trenton, NJ/Ottowa: African World Press/ International Development Research Centre; 2007. p. 3-18. http://dx.doi. org/10.13140/2.1.2539.1043

3. Jones $\mathrm{N}$, Jones $\mathrm{H}$, Walsh C. Political science? Strengthening science-policy dialogue in developing countries. ODI Working Paper 294 [document on the Internet]. c2008 [cited 2017 0ct 24]. Available from: https://www.odi.org/ sites/odi.org.uk/files/odi-assets/publications-opinion-files/474.pdf

4. Banyouko Ndah A. Public policy and policy inappropriateness in Africa: Causes, consequences and the way forward [document on the Internet]. c2010.[cited 2017 0ct 24]. Available from: http://www.academia. edu/318501/Public_policy_and_policy_inappropriateness_in_Africa_ Causes_consequences_and_the_way_forward

5. Olokoshi A. Democratization, globalization and effective policy making in Africa. Ottowa: International Development Research Centre; 2000.

6. Dollar D, Svensson J. What explains the success or failure of structural adjustment programs? Econ J. 2000;110:894-917. https://doi. org/10.1111/1468-0297.00569

7. Ayuk ET, Jones B. From myth to reality: Building capacity for economic policy research in Africa. In: Ayuk ET, Mohamed AM, editors. The policy paradox in Africa: Strengthening links between economic research and policymaking. Trenton/Ottowa: African World Press/International Development Research Centre; 2007. p. 117-130. http://dx.doi.org/10.13140/2.1.2539.1043

8. Hansohm D, Naimhwaka E. Joining forces in policy research networks for policy-making in Africa: The SEAPREN experience. In: Ayuk ET, Mohamed AM, editors. The policy paradox in Africa: Strengthening links between economic research and policymaking. Trenton/Ottowa: African World Press/ International Development Research Centre; 2007. p. 131-149. http://dx.doi. org/10.13140/2.1.2539.1043

9. Toye R. Structural adjustment: Context, assumptions, origin and diversity. Paper presented at: The DGIS/ISSAS Conference on Structural Adjustment and Beyond; 1993 June 1-3; The Hague, the Netherlands.

10. Ajakaiye 0 . Levelling the playing field: Strengthening the role of African research in policy-making in and for sub-Saharan Africa. In: Ayuk ET, Mohamed AM, editors. The policy paradox in Africa: Strengthening links between economic research and policymaking. Trenton/Ottowa: African World Press/International Development Research Centre; 2007. p. 19-39. http://dx.doi.org/10.13140/2.1.2539.1043

11. COHRED. Directory of Selected African Research Networks. 2nd ed [document on the Internet]. [cited 2017 Oct 24]. Available from: http://www. cohred.org/downloads/564.pdf
12. Bhorat $\mathrm{H}$. The nine commandments - a South African case study identifies roles for applied research institutions. In: Ayuk ET, Mohamed AM, editors. The policy paradox in Africa: Strengthening links between economic research and policymaking. Trenton/Ottowa: African World Press/ International Development Research Centre; 2007. p. 185-200. http://dx.doi. org/10.13140/2.1.2539.1043

13. Network Impact and Center for Evaluation Innovation. Framing paper: The state of network evaluation [document on the Internet]. c2014 [cited 2017 0ct 24]. Available from: http://www.networkimpact.org/wp-content/ uploads/2014/09/NetworkEvalGuidePt1_FramingPaper.pdf

14. Hill C. Network literature review: Conceptualizing and evaluating networks. Calgary: The Southern Alberta Child and Youth Health Network; 2002.

15. Provan KG, Milward HB. Do networks really work? A framework for evaluating public sector organizational networks. Public Adm Rev. 2001;61(4):414-423. https://doi.org/10.1111/0033-3352.00045

16. NEPAD SANWATCE. Our vision [webpage on the Internet]. No date [cited 2016 Dec 20]. Available from: http://nepadwatercoe.org/aboutus/our-vision/

17. NEPAD SANWATCE. Expression of interest: 2nd call for membership [webpage on the Internet]. No date [cited 2016 Dec 20]. Available from: http://nepadwatercoe.org/aboutus/expanding-the-network/expression-ofinterest-2nd-call-for-membership/\#Point4

18. Botha AP, Gruenewaldt G, Botha TC. A review of DST support provided to the NEPAD Science and Technology Flagship Programmes. Report TS-109-0012012-REP 1.0. prepared by Technoscene for the Department of Science and Technology; February 2013. Unpublished report.

19. NEDPAD SANWATCE. Our mandate [webpage on the Internet]. No date [cited 2016 Dec 20]. Available from: http://nepadwatercoe.org/aboutus/ourmandate/

20. Dennis R, Parida BP, Mannel D, Kenabatho P, Braune E. Delivering capacity across the SADC region's water sector - JLP 1.4. Report prepared for the European Commission Joint Research Centre [document on the Internet]. c2013 [cited 2016 Dec 20]. Available from: http://nepadwatercoe.org/wpcontent/uploads/JLP1-4_UB_approved.pdf

21. NEPAD SANWATCE. Current projects [webpage on the Internet]. No date [cited 2016 Dec 20]. Available from: http://nepadwatercoe.org/currentprojects/using-iwrm-best-practices-to-develop-appropriate-capacity-andtraining-for-the-benefit-of-sub-saharan-africa-water-security-act4ssaws/

22. NEPAD SANWATCE. Administration and coordination of activities. The AU/ NEPAD Southern African Network of Water Centres of Excellence. Progress report December 2014-2015 [document on the Internet]. c2016 [cited 2016 Dec 20]. Available from: http://nepadwatercoe.org/wp-content/uploads/ SANWATCE-Progress-report-Dec2014-Nov2015FINAL.pdf

23. Botha AP, Gruenewaldt G, Botha TC. A review of DST support provided to the NEPAD Science and Technology Flagship Programmes. Report TS-109-0012012-REP 1.0. prepared by Technoscene for the Department of Science and Technology; February 2013. Unpublished report. p. 54.

24. Botha AP, Gruenewaldt G, Botha TC. A review of DST support provided to the NEPAD Science and Technology Flagship Programmes. Report TS-109-0012012-REP 1.0. prepared by Technoscene for the Department of Science and Technology; February 2013. Unpublished report. p. 52.

25. SANBio. Welcome to SANBio [webpage on the Internet]. No date [cited 2016 Dec 20]. Available from: http://www.nepadSANBio.org

26. SANBio. About us [webpage on the Internet]. No date [cited 2016 Dec 20]. Available from: http://www.nepadSANBio.org/about-us.html

27. Finnish Consulting Group. Mid-term evaluation of BioFISA. Report presented to the Ministry for Foreign Affairs of Finland unit for Southern Africa; March 2012. Unpublished report.

28. SANBio. Celebrating four years of BioFISA [document on the Internet]. c2012 [cited 2017 Oct 24]. Available from: www.nepadsanbio.org/.../sanbionewsletter-celebrating-four-years-biofisa-2009-2012

29. SANBio BioFISA II. BioFISA II Business meets biosciences [document on the Internet]. No date [cited $2016 \mathrm{Dec} 10]$. Available from: http://www. nepadSANBio.org/sites/default/files/BioFISA\%20I\%20Brochure\%20for\%20 Web.pdf

30. SANBio. Business plan 2014-2018 [document on the Internet]. No date [cited 2016 Dec 10]. Available from: http://www.nepadSANBio.org/sites/ default/files/SANBio_Bus_Plan_Proof_1_(1)_Original.pdf

31. SANBio. Annual report 2015. Pretoria: SANBio; 2016. 